\section{Para ver se necesita un cuerpo: vivencias de fragmentación de la figura humana}

To see if a body is needed: fragmentation experiences of the human figure

Resumen: La relación entre imágenes e imaginario se ha estudiado abundantemente desde distintas perspectivas. El cuerpo es el argumento que se ha introducido últimamente, pero muchas veces se introduce de forma lateral. ¿Pero que sucede si el cuerpo es central a la imagen, tanto como la imagen al cuerpo? Es imposible situarse en la producción artística actual sin asumir que sus obras fuerzan una rup tura con las lineas verticales de la subjetivacion, que perciben y ponen en juego la relación cuerpo - imagen con una complejidad inquietante. En las obras de Cohen y de Pombo se hacen presentes algunos de sus rasgos.

\section{Palabras clave: Imagen; Pintura; Cuerpo; medio}

Abstract: The relation between images and imaginary has been studied extensively from different perspectives. The body is the argument that has been introduced lately, but is often introduced on the side. But what happens if the body is central to the image, as much as the image to the body? It is impossible to situate it in current artistic production without assuming that the artworks force a rupture in the vertical lines of subjectivation, which perceive and put into play the body relation - an image with disturbing complexity. In the works of Cohen and Pombo some of these features are present.

Keywords: Picture; Image; Body; media; medium
En algunas representaciones de la figura humana presentes en las obras de los artistas argentinos contemporáneos considerados, Ricardo Rocambole Cohen y Marcelo Pombo, observamos un tipo recurrente de tratamiento que podríamos caracterizar como fragmentación, que propone un desvío de la representación tradicional. Esa fragmentación tematizada, trasladada al tratamiento de la superficie, funcionaría como el señuelo al conducir la experiencia del cuadro fuera de lo visual en la operación de envolvimiento del espectador, al mostrarse como un objeto perdido. Se trata de aquel modo perverso y taimado de involucrar al espectador al que hace referencia Michel Foucault (2015), cuando analiza las estrategias de involucramiento del espectador desplegadas en obra de Édouard Manet y las define como recursos políticos de la obra de arte.

Trataré de sugerir en este texto que algunos conceptos provenientes de la teoría psicoanalítica de raíz lacaniana, son útiles para pensar aquella fragmentación formal observada como una modalidad de encuentro, en el punto en el que autor y espectador comparten la dinámica pulsional que subyace a la imagen

\section{COHEN: FRAGMENTOS DEL CUERPO}

Una de las particularidades en la obra de Ricardo Cohen, conocido como Rocambole, es un tratamiento utilizado en la representación de las figuras que tiene antecedentes en la obra de artistas pop y psicodélicos de la década de los '60 y '70, entre quienes podemos mencionar a Jorge de La Vega ${ }^{4}$ en Argentina y a Emory Douglas ${ }^{5}$ en EE.UU. Podemos llamarlo escala gráfica, pues surge a partir de las exigencias de la baja calidad de los medios precarios de impresión y se trata de un proceso de eliminación de los tonos medios a través de medios entonces fotomecánicos, que define contrastes violentos de valor. Rocambole hace uso de este recurso en una progresión, no totalmente lineal,
[1] COHEN, Ricardo Rocambole (1943). Para ampliar datos biográficos, remito al lector interesa a la página del artista: http:// com.ar

[2] POMBO, Marcelo.(1959) Para ampliar datos biográficos, remito al lector interesado a la página: http:// www.barro.cc/es/ pombo

[3] Pongo este término en relació al uso que hace de él Frederic Jameson, quie caracteriza la sensibilidad posmoderna como fragmentaria (Sánchez Usanos, 2010) A riesgo de cierto exceso de Iteralidad, quisiera señalar que dicha ragmentación psicoanálisis, es psicoanalisis, una vivencia toda ima novedoso es modo en que se tramitarí, cán diferentes modos 
llegando en su utilización a la desintegración casi total de la figura y su asimilación con el fondo.

Un trabajo muy ilustrativo de este modo es El agujero Negro (2001). Se trata de una imagen base que Cohen vuelve a utilizar en a menos otros dos trabajos posteriores. Se muestra una figura que grita y que se toma la cara en ademán de proteger sus ojos, posiblemente, ante algo que lo deslumbra o cuya visión causa horror. El gesto facia es el de mueca doliente más que de grito. A pesar de esto, la figura permanece extática, congelada en un momento, sin otros gestos corporales que la acompañen. La textura representada de la piel es visualmente tectónica, cruzada por surcos y elevaciones, fuertes pliegues y depresiones, entre hendiduras y salientes muy acusadas debido al tratamiento de máximo contraste en lo representado. Su cuerpo, de composición descentrada, sale un poco fuera de campo y está cruzado por tensiones superficiales y por arrugas muy fuertes. El brazo que se levanta para ocultar los ojos es un brazo descolocado, cuyo movimiento no hace descender el hombro, la cintura acromial, como sería esperable, para acompañar la elevación del brazo. La falta de naturalidad le agrega violencia al gesto y el brazo, entonces presumiblemente quebrado o deforme, le suma dramatismo al desplazamiento. El fondo es negro pleno, de textura uniforme, y produce un notable contrapunto a modo de un telón de fondo plano que exalta el trabajo de la textura visual descrita en la figura.

La misma imagen retorna en un trabajo titulado Memoria (2006), pero ahora compuesta en forma más central y estable, y representada en negativo, es decir, con los valores originales invertidos. La inversión de los valores le agrega intensidad a la idea de fragmentación: la figura se desgrana en formas negras dentro un continente blanco sobre fondo oscuro, donde la luz de la imagen parece provenir de un interior incandescente, como si se tratara de una brasa encendida. El fondo, a

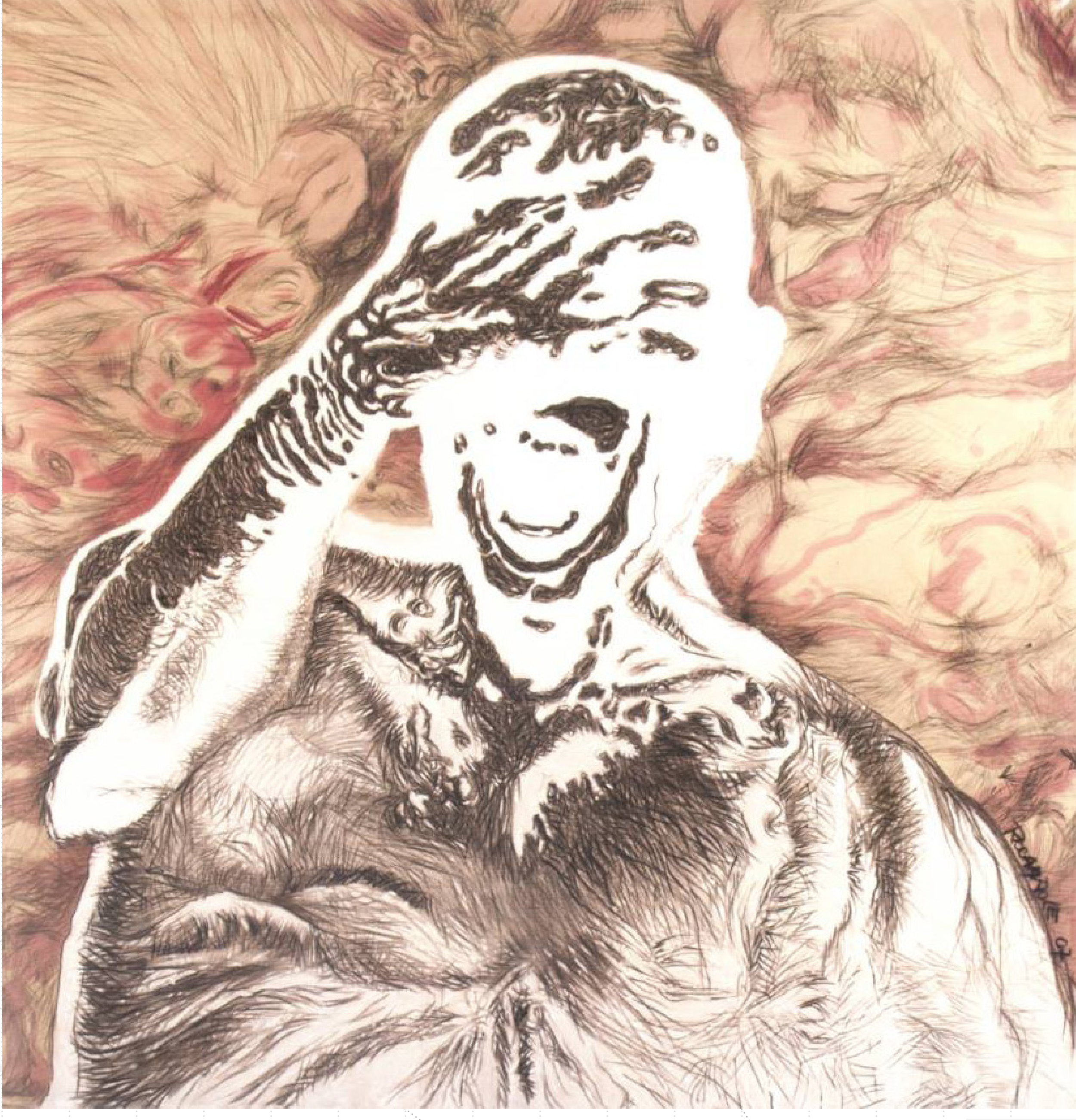

Figura 1. ¿Todavía? (2007), Ricardo Cohen. Acrílico sobre tela. $180 \times 180 \mathrm{~cm}$. Fuente: Imagen escaneada de (COHEN, 2014, p.43). 
su vez, es rojo y está físicamente texturado por un fuerte rayado sobre la capa de materia que se asemejan a cortes, en oposición a lo plano y acromático de la figura.

La misma figura retorna en otra clave en la que se explotan las distintas modulaciones del trazo y del gesto, propias del lenguaje del dibujo. La obra se titula ¿Todavía? (2007) (Figura 1). No solo conserva la inversión de valores de la última versión descripta, que le permite conservar la característica señalada en la iluminación, sino que dentro de las formaciones que componen el cuerpo fragmentado se establecen modulados sobre la base de trazos que le agregan a cada fragmento profundidad y, al mismo tiempo, independencia, con lo que ya estos no se presentan completamente planos, sino que vibran y están surcados por tensiones.

La figura tiene centralidad, pero, en relación con el primer trabajo, está ampliada, avanza sobre el campo y exhibe en el sector inferior derecho una ampliación, un agregado en relación con la figura original. Esta presencia parece una mutación o el crecimiento de algo anómalo adosado y, al mismo tiempo, pudiera ser el mismo cuerpo el que se amplifica, se expande, se abre y se aplasta contra el plano del espectador. El fondo que en otras versiones fue liso y luego texturado directamente sobre la materia, en este caso está texturado de forma más óptica, sutil y coloreada con algo de rojo lavado que remeda una consistencia orgánica, de mucosa intestinal o tejido interno.

En una obra de 2002, El Castigo, el mismo tratamiento de contraste violento aparece en la cabeza que conforma el cuadro. El castigo no está representado directamente, sino que se puede leer en la mirada del sujeto, como si proviniera de su interior, en forma de culpa o autopunición. El esclavo aqui representado es uno de los modelos predilectos de Cohen, así como lo son sus temas asociados, la libertad y el castigo, y también es el motivo de la obra que le ha valido el

DARALELӨ3I reconocimiento del gran público en Argentina. En esta imagen la mirada del esclavo surge de las sombras. La luz que deja ver sus rasgos (algunos puntos aislados de la frente, los ojos, los pómulos, la nariz, el mentón, la boca) los hace emerger de un continente negro, que casi se funde con los contornos sobre un fondo rojo oscuro, en contraste

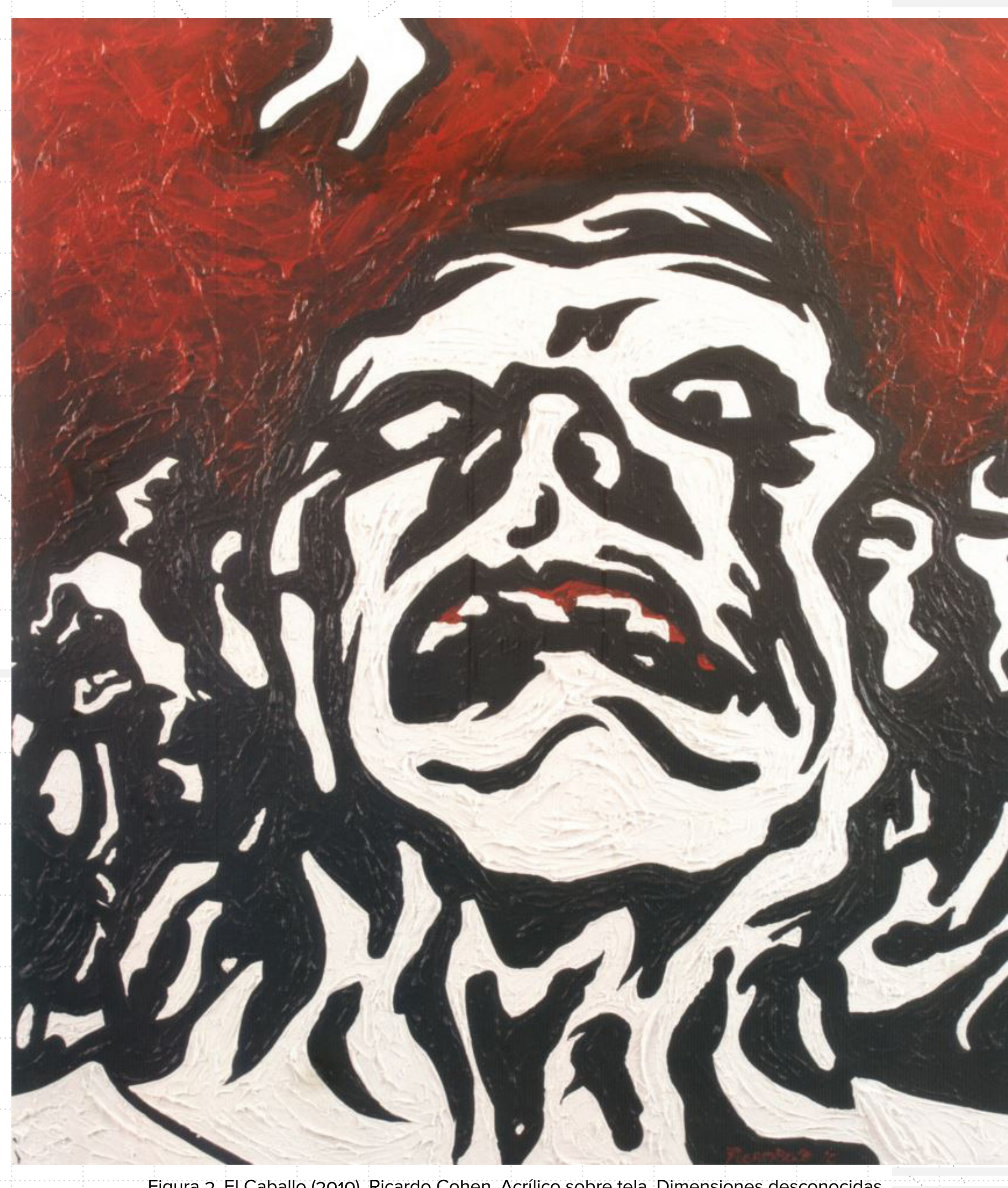

Figura 2. El Caballo (2010), Ricardo Cohen. Acrílico sobre tela. Dimensiones desconocidas,

Fuente: Imagen escaneada de (COHEN, 2014, 104). 
mínimo, apenas sugerido en la textura del rostro que atrapa algo de la luz ambiente.

Otro trabajo del año 2010, El Caballo (Figura 2), presenta como único protagonista una figura que parece estar disolviéndose en un gesto de dolor, de sorpresa o de enojo, y que se confunde con el fondo Está rodeada de fragmentos que parecen ser parte de otras figuras o que son los desprendimientos del personaje central, productos de la erosión de corrientes provenientes del fondo, como en una costa de fiordos.

En Nueva Ignara (2012), la figura ya no es de una humanidad anómala, sino lisa y llanamente un monstruo. Replegada sobre ciertos límites que contornean un ser antropomórfico pero siniestro, conserva los pliegues y las arrugas y deja entrever una consistencia ajada, con rasgos distorsionados, hendidos y fragmentados.

Los trabajos descriptos, puestos en una secuencia temporal, se podrían asimilar al proceso de descomposición de un cuerpo. En algunos dibujos antiguos que parecen presentar antecedentes de este recurso, como La antigua pregunta (1986), las partes constituyentes del cuerpo representado se separan, crecen, se distorsionan, y develan en el tratamiento de modelados su peso y la consistencia propia de tejidos diferenciados. Esta imagen podría ser un antecedente directo del cuadro Memoria, antes mencionado, con la particularidad de presentar como fondo de la representación una multitud de figuras que componen una trama, recurso que plantea otra problemática que emerge en algunas obras de Cohen, a saber: la tensión entre lo colectivo y lo individual, a través de la dificultad de integrar sus respectivas representaciones. Las partes del cuerpo se hacen extrañas, se autonomizan, y los intersticios así liberados dejan que la imagen de la multitud pase a través de los personajes como penetra en la constitución de la identidad propia la mirada de los otros.

DARALELO3
Cohen utiliza otra técnica o un recurso que traduce en forma directa la mirada de fragmentan corporal, como la que pone en juego en su obra La mano izquierda en la oscuridad (2010). Esta pintura está realizada sobre un fondo negro, es decir, extrayendo las figuras mediante las luces, un recurso goyesco. El centro está ocupado por

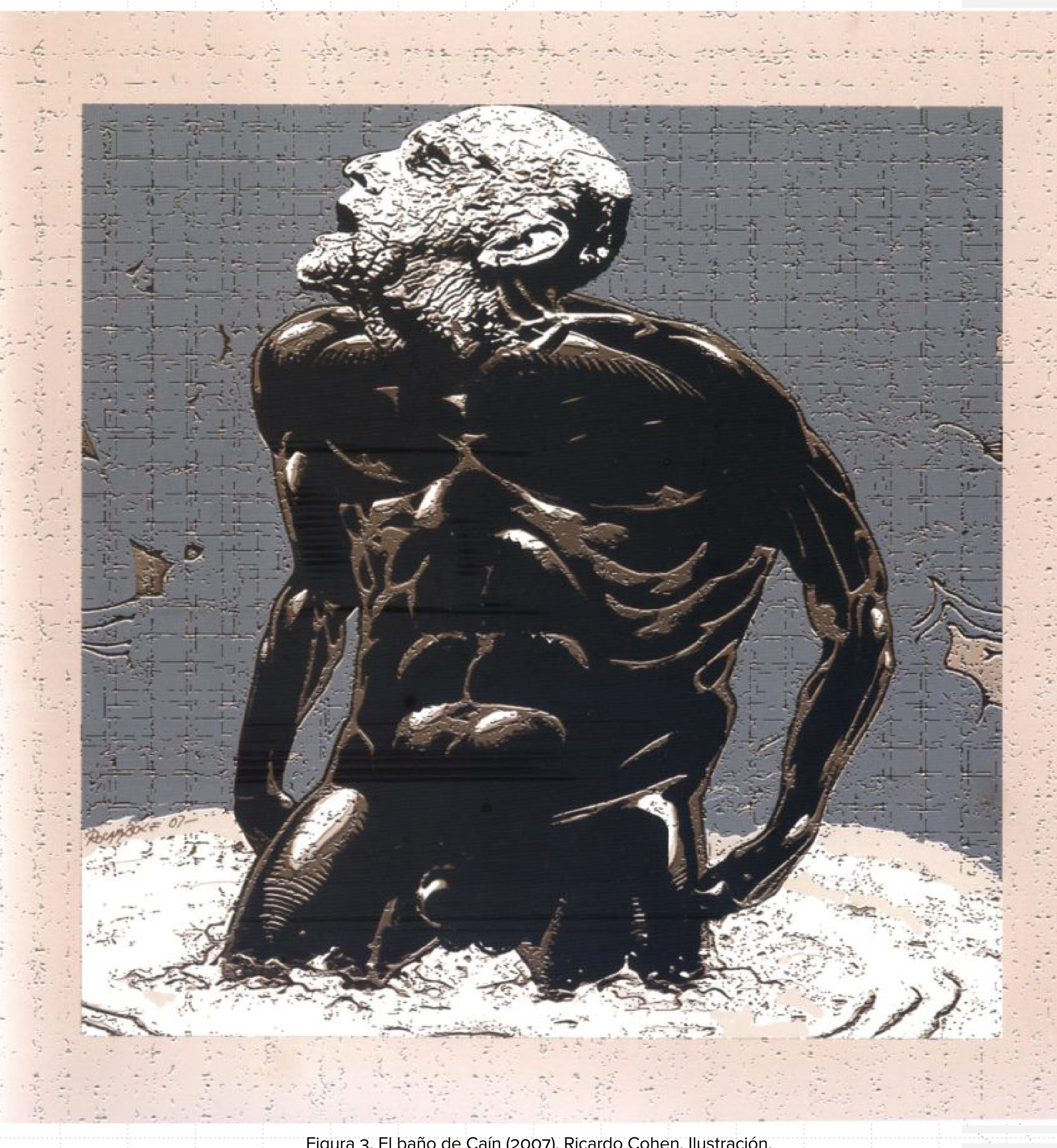

Figura 3. El baño de Caín (2007). Ricardo Cohen. Ilustración.

Fuente: Imagen escaneada de (COHEN, 2014, 107). 
una figura que grita y que se toma la cabeza, superpuesta a una trama regular de fondo que recuerda tanto a una alambrada como a las uniones de un revestimiento azulejado, propio de una sala de hospital. Este cerco es rígido y envolvente, cierra un espacio, mientras la figura hecha de puntos de luz tiene un carácter móvil, transitorio, vibrátil y el fondo se cuela por entre las partículas-pinceladas que la componen.

En otras imágenes el estallido en partículas del cuerpo representado se ha sustituido por la proliferación de modos y de recursos dispuestos en un mismo plano temporal. En la figura representada en El baño de Caín (2007) (Figura 3), hay una oposición en el tratamiento de un cuerpo compuesto por músculos marcados que tiene un superficie oscura, lisa y brillante, como de basalto pulido, mientras la cabeza anciana del personaje, blanquecina, apergaminada y rugosa, parece hecha de piedra calcárea, con aspecto poroso. El gesto del personaje que grita y que parece emerger de una laguna viscosa es un gesto de dolor, que es difícil de ubicar como propio de un nacimiento o cercano a la extinción.

\section{POMBO: LA SUPERFICIE QUE MIRA}

En las obras de Marcelo Pombo la captura del espectador se centra en su utilización de la materia. Sus diferentes calidades son manipuladas con arreglo a una sensualidad inmediata. Las superficies son transformadas, enriquecidas sobre un vector de lujo y suntuosidad.

Desde sus trabajos con objetos, como Winco (1986), intervenido con chorreados y con collages, o la serie de los discos, posiciona los objetos para que encuentren al espectador fuera de escena. Esta estrategia se va a ir pasando a sus cuadros sin perder potencia, es decir, del objeto al cuadro objeto, como en la obra La navidad de San Francisco Solano (1991), en la que la calidad material del cartón es protagónica, como el polietileno de las bolsas de residuo que utiliza como materia prima en su cuadro Vitraux de San Francisco Solano, del mismo año. Materialidades bajas, relacionadas a un entorno humilde, pobres pero nunca en clave de denuncia ni de desgarramiento, sino que apuesta a elevar la dignidad de estos materiales vulgares a la condición de nobles, como si fuera posible beatificarlos, adherirles un resplandor nuevo y, por extensión, santificar la vida humilde de los usuarios y, de esta manera, actuar sobre la belleza del contexto.

Con algunos retornos verificables, la dirección de la poética de Pombo va desde el objeto hasta el cuadro, pasando por el cuadro-objeto. $Y$ en el traslado de la seducción material propia del objeto al cuadro le ha significado buscar un procedimiento adecuado, que logra apostando a una técnica para disolver meticulosamente el plano en partículas perladas y convertirlo en una superficie preciosa. Hay un antecedente importante de este recurso en su obra El niño mariposa (1996) y antes, incluso, en Xuxa (1993). Se trata de una forma de aplicar el esmalte sintético, goteándolo sobre la superficie horizontal del cuadro valiéndose de un gotero, una pipeta, un palillo de brochette o de sushi, en una operación muy paciente y delicada, color tras color, guardando entre uno y otro el tiempo de secado necesario y respetando la dilución exacta. El color base, seco o casi seco, absorbe parcialmente la nueva gota de color, que se convierte en un punto. Se obtiene una perla, una especie de óvulo o de huevo de pez o de célula de paredes traslúcidas y de núcleo reconocible.

Estos puntos de compleja factura son una constante en la gran mayoría de sus trabajos a partir de 1993 y resultan utilizados en casi todas las figuras representadas, en oposición a un fondo frecuentemente liso o que presenta otros procedimientos texturales. En su obra Árboles enamorados (2002) (Figura 4), el tratamiento retorna visible en los brotes de las ramas, pero los troncos comparten ese tratamiento en otra tonalidad. Aquí, los árboles, que están compuestos por esta textura puntiforme, pueden ser asimilados a los cuerpos de dos amantes. 
pequeñísimos rostros y, a veces, de texturas puntiformes parecidas a pequeños ojos que recuerdan el goteo (Figura 6).

En Manifestación flotante (2006) cada punto se independiza como un ser autónomo y parece corresponder a un integrante de la multitud que flota con una exuberancia festiva pero ordenada. En otro trabajo del mismo año, Escombros flotantes, de planteo muy similar, el punteado se limita al registro de la textura vegetal y la composición es una proliferación de restos organizados de manera caótica. Aquel goteo que en las primeras obras de POMBO era propio de la superficie de algunos objetos o figuras representadas, en los cuadros de su obra posterior toma el lugar de la representación del cuerpo en forma de una trama de ojos y bocas, menos asunto de una visualidad pura y más cerca de su lugar del objeto en la mirada.

\section{IMAGEM: MEDIO Y CUERPO}

En las descripciones anteriores he querido señalar algunas posibles diferencias y analogias en los tratamientos de las figuras y de la materia (real o representada) en las imágenes estudiadas. La inmediatez del esquema que surge de una lectura fenomenológica de la imagen, reproduce la división tradicional de cuerpo/alma y su correlato materia/idea, nos aparta de la capacidad de comprender la imagen de modo sustantivo.

Como aporte a este problema, Hans BELTING (2009) introduce la consideración de nuestro cuerpo como medio de las imágenes. Rechaza la tradición aristotélica que reduce la imagen a lo cognitivo, argumentando que tiene un cuerpo propio que no se limita al soporte material. Recíprocamente, el cuerpo humano no puede reducirse al organismo, sino que además, es sede de determinaciones imaginarias y simbólicas. La imagen vuelve entonces al mundo de los cuerpos a través de la dinámica medial: « Puesto que una imagen carece de cuerpo requiere de un cuerpo para corporizarse» (BELTING, 2009: 22). BELTING propone la tríada imagen-medio-cuerpo como un triángulo inseparable para interpretar las imágenes.

Otro tanto concluye Richard WOLLHEIM (1997) al preguntarse por los mecanismos estructurales que hacen de una superficie pintada una obra. Durante el proceso de la creación de un cuadro, se despliega un mecanismo a partir de las primeras marcas, que va conformando la intención del artista, por el cual va abstrayendo aspectos de lo que está elaborando, que no consideraba a priori y que utiliza como rasgos constitutivos de su actividad futura. WOLLHEIM Illama a esto «tematización» (1997: 27), estrategia que persigue darle un significado a la superficie resultante, para que por su intermedio el espectador sienta su estado mental (WOLLHEIM, 1997). El significado descansa en la experiencia inducida en el espectador para que, llevado por las intenciones del artista, repare en él. La tematización se había considerado como un proceso puramente mental, pero «[...] se da dentro del fragmento de nuestra psicología que es esencialmente corporal [...] exige un ojo [...] y exige una mano» que puedan realizar distinciones dentro del rasgo tematizado (WOLLHEIM, 1997: 34). Desde la tradición analítica en que se inscribe WOLLHEIM hay un reconocimiento de que la imagen artística, en su factura, involucra lo corporal.

\section{LACAN: EL CUERPO Y LA IMAGEN}

En el marco de la teoría psicoanalítica, la imagen tiene un papel muy importante en la constitución del sujeto. En su artículo El estadio del espejo como formador de la función del Yo [je], tal como se nos revela en la experiencia psicoanalítica (2005: 86), Jacques LACAN describe la formación del yo como transformación en el sujeto a partir de la asunción de su propia imagen en el espejo. Esto es posible debido a la prematuración en el desarrollo de la percepción visual y a las carencias en el desarrollo motriz de la criatura humana de seis meses. El encuentro con su propia imagen genera, a partir de su captación como gestalt, una discordancia entre 
la síntesis de la imagen y la falta de coordinación vivida como imagen de cuerpo fragmentado. La tensión agresiva que se produce es resuelta en una identificación primaria con lo semejante, con esa imagen especular que da forma al yo, bajo la mirada de un adulto.

Luciano Lutereau (2009) señala dos notas fundamentales derivadas de esta experiencia. Por un lado, la imagen es una totalidad perceptiva de acuerdo con las leyes de la Gestalt. Por el otro, la imagen es condición de constitución de la realidad. Si el movimiento del cuerpo es fundamental en la constitución del espacio, la realidad es imaginarizada en tanto espacio realizado en la experiencia como espacio estructurado para ese cuerpo. La realidad es, en este sentido, apropiada como imagen (LUTEREAU, 2009).

Estas definiciones, que sitúan la imagen en el vínculo entre el registro de un cuerpo real fragmentado y la imagen especular, van a completarse con la introducción del registro de lo simbólico. Para poder explicar la articulación de los diferentes órdenes de la realidad, tal como se hacen presentes en la constitución del yo en la imagen, Lacan (1991) utiliza modelos tomados de la Óptica, porque la diferencia planteada en estos entre imágenes reales e imágenes virtuales, definidas de acuerdo cómo se construyen en el ojo a partir de la luz que reflejan los objetos, permite estudiar el vínculo entre lo real y los fenómenos imaginarios.

Al partir de un primer esquema en el que sitúa el estadio de espejo ${ }^{6}$, introduce lo simbólico a través de un espejo plano que provoca una imagen virtual. «Al mostrar la imagen donde no está, esta imagen virtual abre un campo de referencia negativizada que también podría llamarse presencia de una ausencia o falta» (LUTEREAU, 2009: 35). Aparece, entonces, un rasgo nuevo: la negatividad del referente en la constitución de la gestalt asumida como imagen corporal. La imagen de los objetos se revela como constituida a partir del cierre del objeto y de su recupero como ausencia.
Esta introducción de transforma lo imaginario. Si lo simbólico da existencia a lo que no se presenta ni representa, la representación de lo representado, la falta, lo más importante de lo imaginario es, a partir de entonces, que en la imagen se representa lo que no se puede ver. El estadio del espejo introduce la imagen como el lugar donde hay presencia en lo que se puede ver de algo que no se ve. De ahí que la imagen hace de pantalla de lo que no podemos ver. Echa un velo sobre lo que no se ve y el velo hace existir algo de la nada, hace ver que algo no se ve, convierte la nada en ser. Si hay algo y no hay nada es porque hay algo en algún lugar (MILLER, 1994).

Decíamos que en este estadio hay una transformación del sujeto a través de su asunción en una imagen. La mencionamos como Gestalt, es decir, una imagen pregnante que aquí es la imagen del cuerpo. A partir de entonces esta imagen corporal estará mediando al cuerpo biológico en su intercambio y se proyectará en distintas superficies. Para Miller (1994) esto significa que el cuerpo es distinto del organismo : no es un real biológico, sino una forma, por lo tanto imaginario; lo que lleva a Lacan a decir que lo imaginario es el cuerpo. Esto es importante, porque el goce es impensable sin cuerpo y, por lo tanto, se vincula a lo imaginario (MILLER, 1994).

\section{NASIO: LAS IMÁGENES DEL CUERPO}

En la perspectiva del psicoanálisis, como hemos visto, cuerpo e imagen son indisociables. NASIO (2008) define la imagen como el resultado de una correspondencia virtual entre dos objetos. En este caso de la imagen del cuerpo ${ }^{7}$ sería el doble virtual de su objeto real que es nuestro cuerpo. Esta imagen no puede ser homogénea; está compuesta por una infinidad de imágenes psíquicas que provienen del interior y de la superficie de nuestro cuerpo real. Además de modelada por una multiplicidad de proyecciones inconscientes está animada y alimentada por la libido.
[7] Con esta expresión NASIO se cuida muy estratégicamente de hablar imácon dropia ingen propla porque justamente pretende desmontar sulocalizacín su localización y pertenencia, lenguaje. 
Donde no hay libido no hay conmoción, en consecuencia, no hay imagen. La imagen tiene necesidad de libido para existir y la libido tiene necesidad de la imagen para circular.

El cuerpo puede pensarse a través de la trilogía de registros lacanianos: lo simbólico, lo real y lo imaginario: como cuerpo real (el que siento), cuerpo imaginario (es el que veo) y cuerpo simbólico (es el que nombro) (NASIO, 2008). El cuerpo real es el cuerpo sensorial, el cuerpo erógeno, del deseo y del goce, ese que se va degradando inexorablemente. Es real no por ser sólido y palpable, sino porque en él late la vida. El cuerpo real es el cuerpo que no pueden asir los sentidos, ni las palabras, ni los símbolos, el cuerpo que se sustrae a toda aprehensión directa, entera y definitiva. No es real por orgánico, sino que el término real define la vida que lo anima y no la carne. Es lo que se nos escapa al ser humano que somos.

El cuerpo imaginario es el cuerpo que veo, principalmente en el espejo, pero también puede ser en una sombra o una silueta, una mancha, una instantánea del cuerpo captado de una vez y como un todo, que persiste en nosotros desde nuestra infancia. Puede aparecernos en un soporte (pantalla, escultura, dibujo, fotografía) o aún en la silueta que reconocemos en la apariencia de nuestros semejantes, pero siempre fuera de nosotros. Es una imagen que conmueve, que cautiva y que, a veces, me contraría, me amenaza o me vuelve una impresión decepcionante. Esta imagen también es una imagen perforada, cuyo agujero metafórico representa la energía libidinal que galvaniza mi mirada cuando me reflejo en el espejo; allí puedo ver todo menos lo que siento.

En cuanto al cuerpo simbólico, el cuerpo es en sí mismo una metáfora, la más elocuente de todo lo vivo e, inversamente, el objeto más simbolizado, el que suscita más metáforas. El símbolo sustituye, pero también engendra la realidad, por lo que a veces se convierte en lo que Lacan llama significante. El cuerpo simbólico o significante es la singularidad corporal que pasa a ser significante, como representativa del sujeto, y le impone su realidad. Según Juan David Nasio (1994) hay tres estados del cuerpo propio percibido, conformados por su propia imagen. La imagen del cuerpo sentido es una imagen mental inconsciente, que puede permanecer en ese estado o hacerse consciente, o exteriorizarse en un acto. Es una imagen perforada por la libido y en mosaico como el cuerpo acribillado de sensaciones, de deseo y de goce del que es doble. La estructura de esta imagen real del cuerpo sería una superficie compuesta de microimágenes no figurativas, móviles, cambiantes y en permanente reimpresión con las imágenes de la infancia, todas investidas por la libido, representada por un agujero. Este representa la ausencia de representación de la libido en la imagen tanto en la imagen real y como la especular del cuerpo ambas atravesadas por el flujo libidinal que las irriga, las acerca y las fusiona.

La imagen del cuerpo visto es la imagen especular de nuestra silueta, está tan perforada por la libido como la imagen mental de las sensaciones. La imagen del cuerpo significante no es consciente, ni inconsciente, ni actuada, sino que es nominativa, y el nombre es el doble de la particularidad física que singulariza el cuerpo.

La imagen corporal no puede corresponderse exactamente con el cuerpo real, porque las zonas erógenas se presentan como manchas opacas en el lugar del cuerpo real donde la libido satura. Allí, la imagen se presenta perforada o, también, con un foco incandescente y enceguecedor llamado falo imaginario, simbolizado (- $\Phi$ ). Este agujero es un verdadero vacío aspirante que mantiene unidos a los elementos de la imagen por medio de una fuerza centrípeta. El (- $\Phi$ ) es el verdadero organizador de la estructura e impulsor de la imagen.

Tenemos que decir que esta imagen perforada no es una totalidad plena y con apariencia homogénea, sino, una composición de representaciones de fragmentos corporales múltiples, tanto una oreja como el tono 
de una voz o el olor de un vestido. La imagen del cuerpo es una imagen compuesta, una trama de microimágenes parciales. La percepción de mi cuerpo no solo produce imágenes fragmentarias, sino que, además, nunca es una percepción directa del cuerpo real. Esta imagen no cesa nunca de producirse y permanece siempre en estado de esbozo. Construida desde la vida fetal, esta imagen inconsciente dinámica, causal, libidinal, perforada por el falo y compuesta solo existe con la condición de que ese cuerpo percibido esté habitado por la presencia del otro.

Tras el cuerpo de toda imagen acecha la imagen del cuerpo, en un bucle que nos permite constituir aquello que llamamos realidad; es allí, en esa inadecuación constitutiva que el lenguaje sutura, dónde radica lo irrepresentable y la posibilidad del goce ${ }^{9}$

Algunas representaciones de la figura humana tienen el poder de afirmar nuestra visión, nos tranquilizan. Otras, como las obras de Cohen y las de Pombo, por vias diferentes, nos enfrentan con nuestra ceguera.

Si en Cohen la superficie conduce a los cuerpos hacia una inminente desintegración, en Pombo, se llega a esta instancia a través de una saturación de goce, conducido por un exceso de orden que tramita el peligro de la disolución de manera opuesta; quizá señalando que todo nuevo reagrupamiento de lo libidinal, toda puesta en estructura de los fragmentos es tan inevitable como efímera. La integridad del cuerpo está bajo amenaza; pero la disolución es una posibilidad que afirma y anticipa también, en el extremo, la capacidad de un ordenamiento distinto, de una reconstitución otra de los objetos a partir de la subversión del deseo por un desborde de lo pulsional.

Lo político de estas operaciones subyace en que captan al espectador a partir de presentarle posibilidades de reconfigurarse como sujeto de una disposición deseante distinta. Lo hacen respetando su singularidad, sin obturar el vacío con un modelo, sino conectando con su capacidad de convertirse en un otro de sí mismo.

\section{REFERENCIAS BIBLIOGRÁFICAS}

AA.VV. (2006) Pombo. Buenos Aires: Adriana Hidalgo editora.

BELTING, Hans (2009). Antropología de la imagen. Buenos Aires: Katz.

COHEN, José Ricardo. (2014) Arte, diseño y contracultura/

Rocambole. La Plata: Troupe Comunicación.

EVANS, Dylan (2005). Diccionario introductorio de

psicoanálisis LACANiano. Buenos Aires: Paidós.

FOUCAULT, Michel. La pintura de Manet. Buenos Aires: Fondo de Cultura Económica. 2015.

LACAN, Jacques. El estadio del espejo como formador de la función del Yo [je], tal como se nos revela en la experiencia psicoanalítica. En Escritos I, páginas 86 a $93.1^{\circledR}$ Ed., $2^{\text {a }}$ reimpresión. Buenos Aires, Siglo Veintiuno. Editores. 2005, (primera edición francesa: 1966, Éditions du Seuil).

\section{Seminario I. Los escritos técnicos de Freud (1953-}

954).1 $1^{\mathrm{a}}$ edición, 19a reimpresión. Buenos Aires Ed. Paidós. 1991 (primera edición francesa: 1975, Éditions du Seuil).

\section{Seminario VII. La Ética del Psicoanálisis. (1959} 960).1 $1^{\mathrm{a}}$ edición, $14^{\mathrm{a}}$ reimpresión. Buenos Aires, Ed. Paidós. 2005. (primera edición francesa: 1973, Éditions du Seuil).

De los nombres del padre. $1^{\text {a }}$ edición, $3^{\mathrm{a}}$ reimpresión. Buenos Aires. Editorial Paidós. 2007 (primera edición francesa: 2005, Éditions du Seuil).

LUTEREAU, Luciano . Lacan y el barroco. Hacia una estética de la mirada. Buenos Aires. Ed. Grama, 2009.

MILLER, Jacques-Alain. Las cárceles del Goce. En AA.VV. Imágenes y miradas Ponencias de las Terceras Jornadas Anuales de la Escuela de Orientación Lacaniana. Páginas 13 a 32. Buenos Aires, Ediciones de la EOL, 1994. 
SÁNCHEZ USANOS, David. Reflexiones sobre la

posmodernidad. Una conversación de David Sánchez Usanos

con Frederic Jameson. Madrid, Abada Editores, 2010

WOLLHEIM, Richard .La pintura como arte. Madrid, Ed. La

Balsa del Medusa, 1997. (1 ${ }^{\mathrm{a}}$ ed. En inglés 1987). 